\title{
RESEARCH
}

Open Access

\section{Spatiotemporal characterisation and risk factor analysis of malaria outbreak in Cabo Verde in 2017}

\author{
Adilson José DePina ${ }^{1,2^{*}}$ (D), Alex Jailson Barbosa Andrade ${ }^{3}$, Abdoulaye Kane Dia ${ }^{1,4}$, António Lima Moreira ${ }^{5}$, \\ Ullardina Domingos Furtado ${ }^{6}$, Helga Baptista ${ }^{6}$, Ousmane Faye ${ }^{4}$, Ibrahima Seck and El Hadji Amadou Niang ${ }^{4,8}$
}

\begin{abstract}
Background: Cabo Verde is a country that has been in the pre-elimination stage of malaria since the year 2000. The country is still reporting cases, particularly in the capital of Praia, where more than $50 \%$ of the national population live. This study aims to examine the spatial and temporal epidemiological profile of malaria across the country during the 2017 outbreak and to analyse the risk factors, which may have influenced the trend in malaria cases.
\end{abstract}

Methods: Longitudinal data collected from all malaria cases in Cabo Verde for the year 2017 were used in this study. The epidemiological characteristics of the cases were analysed. Local and spatial clusters of malaria from Praia were detected by applying the Cluster and Outlier Analysis (Anselin Local Moran's I) to determine the spatial clustering pattern. We then used the Pearson correlation coefficient to analyse the relationship between malaria cases and meteorological variables to identify underlying drivers.

Results: In 2017, 446 cases of malaria were reported in Cabo Verde with the peak of cases in October. These cases were primarily Plasmodium falciparum infections. Of these cases, 423 were indigenous infections recorded in Praia, while 23 were imported malaria cases from different African countries. One case of P. vivax infection was imported from Brazil. Spatial autocorrelation analysis revealed a cluster of high-high malaria cases in the centre of the city. Malaria case occurrence has a very weak correlation $(r=0.16)$ with breeding site location. Most of the cases $\left(69.9 \%, R^{2}=0.699\right)$ were explained by the local environmental condition, with temperature being the primary risk factor followed by relative humidity. A moderately positive relationship was noted with the total pluviometry, while wind speed had a strong negative influence on malaria infections.

Conclusions: In Cabo Verde, malaria remains a serious public health issue, especially in Praia. The high number of cases recorded in 2017 demonstrates the fragility of the situation and the challenges to eliminating indigenous malaria cases and preventing imported cases. Mosquito breeding sites have been the main risk factor, while temperature and precipitation were positively associated with malaria infection. In light of this study, there is an urgent need to reinforce control strategies to achieve the elimination goal in the country.

Keywords: Malaria, Spatiotemporal characterisation, Cabo Verde

\footnotetext{
* Correspondence: Adilson.Pina@ccssida.gov.cv

'Ecole Doctorale des Sciences de la Vie, de la Santé et de l'Environnement

(ED-SEV), Université Cheikh Anta Diop (UCAD) de Dakar, Dakar, Sénégal

${ }^{2}$ Programa de Pré-Eliminação do Paludismo, CCS-SIDA, Ministério da Saúde e

da Segurança Social, Praia, Cape Verde

Full list of author information is available at the end of the article
}

(c) The Author(s). 2019 Open Access This article is distributed under the terms of the Creative Commons Attribution 4.0 International License (http://creativecommons.org/licenses/by/4.0/), which permits unrestricted use, distribution, and reproduction in any medium, provided you give appropriate credit to the original author(s) and the source, provide a link to the Creative Commons license, and indicate if changes were made. The Creative Commons Public Domain Dedication waiver (http://creativecommons.org/publicdomain/zero/1.0/) applies to the data made available in this article, unless otherwise stated. 


\section{Introduction}

Despite global control efforts, malaria remains a major public health issue worldwide. According to the last World Health Organization (WHO) malaria report, nearly half of the world's population is at risk [1]. For instance, in 2016, malaria transmission was reported in 91 countries and territories, mainly on the African continent, in Southeast Asia and in the eastern Mediterranean region [1-3]. The global health community has reinforced efforts against the disease with a renewed malaria elimination goal. By the end of 2016, at least 44 countries reported fewer than 10,000 cases, while 21 countries, including Cabo Verde, were eligible for malaria pre-elimination by $2020[4,5]$.

Cabo Verde is an archipelago of 10 islands in the Atlantic Ocean, approximately $570 \mathrm{~km}$ from the western African coast. The population of the country was estimated to be 537,661 inhabitants [6]. The archipelago is classified as a lower middle-income country with a gross domestic product (GDP) per capita of 2998 USD [7]. In the late 1950s, malaria was endemic in the country with 5000 to 15,000 cases per year and more than 200 malaria-related deaths [8]. Early control efforts through indoor residual spraying (IRS) with dichlorodiphenyltrichloroethane (DDT) and larval source management using both chemical larvicides and larvivorous fish have achieved the elimination of malaria twice for the country. The disease was then re-introduced twice afterwards $[8,9]$.

Presently, malaria is unstable throughout the country, with the burden being disproportionately high among men [10]. The country is characterised by a low malaria incidence of fewer than 1 case per 1000 inhabitants per year, despite the recent outbreak in 2017. In a previous study, we showed that indigenous cases were restricted to the islands of Santiago (mainly in the capital city of Praia) and Boavista. Imported cases from the African continent were more widespread across the country [10].

Entomological and parasitological surveys have reported Anopheles arabiensis, a member of the Anopheles gambiae complex, as the sole malaria vector in the country, and Plasmodium falciparum was responsible for almost all the malaria cases recorded between 2010 and 2016 [8, 10]. The archipelago's malaria control programme integrates rapid diagnostics and quick treatment of all confirmed cases, as well as preventive measures, including vector control with IRS and larval source management. All confirmed cases are systematically treated with at least 3 days of hospitalisation and a reactive control response, including epidemiological and entomological surveys and spraying around the index case $[11,12]$.

Since Cabo Verde is targeting malaria for elimination by 2020 , it is critical to evaluate the malaria transmission pattern in the country, considering the environmental and climatic factors influencing the disease epidemiology, as well as its control [13]. Furthermore, the integration of Geographical Information System (GIS) tools to map malaria incidence over a given space with the power of spatial statistical methods offers a robust predictive tool for the control of malaria [14-16]. The maps generated with GIS tools provide a visual representation of the cases across areas of interest, thereby enabling for the identification and location of areas of highest risk, where actions need to be targeted [16-18]. These advancements will further inform evidence-based decisions for the best use of limited resources in a cost-effective manner [18-21].

Studies throughout the world have indicated changes in malaria incidence due to patterns of environmental conditions [18-21]. In Cabo Verde, no study has examined the relationship between malaria epidemics and climatic factors, leading to the interest to better understand the spatial and temporal characteristics of malaria in the country, especially for transmission hotspots, such as in Praia.

In this study, we analysed epidemiological and/or environmental factors of risk potentially associated with the recent malaria outbreak recorded in Cabo Verde. This study provides critical epidemiological information which could be used by Cabo Verde decision makers to better target control strategies for the country's elimination goal.

\section{Methods \\ Study area}

Surrounded by the sea, Cabo Verde is an archipelagic country characterised by a moderate climate and stable temperatures with extreme aridity. February is the coldest month $\left(<20^{\circ} \mathrm{C}\right)$, while August and September are the hottest and wettest months, respectively (with temperatures $>20^{\circ} \mathrm{C}$ ). The Cabo Verde islands are profoundly affected by the two-season nature of the intertropical convergence zone (ITCZ). The climate of the archipelago and precipitation levels is attributed to the ITCZ with an average annual rainfall of $197 \mathrm{~mm}$ [22].

The study used the national data for malaria recorded in 2017. Spatial autocorrelation and cluster analysis were used for indigenous cases from Praia, the capital. Located on the largest island, Santiago, Praia, is described as a set of plateaus and respective surrounding valleys. Praia hosts 159,057 inhabitants representing approximately $29.2 \%$ of the national population in an area of $102.6 \mathrm{~km}^{2}$ and accounts for $43.2 \%$ of the overall national GDP (Fig. 1).

Praia has a desert climate (BWh, in the Köppen-Geiger climate classification) with a short rainy season and a dry season that runs from December to July and is characterised by constant winds (harmaton) from the Sahara Desert. The temperature is moderate, with the maximum 


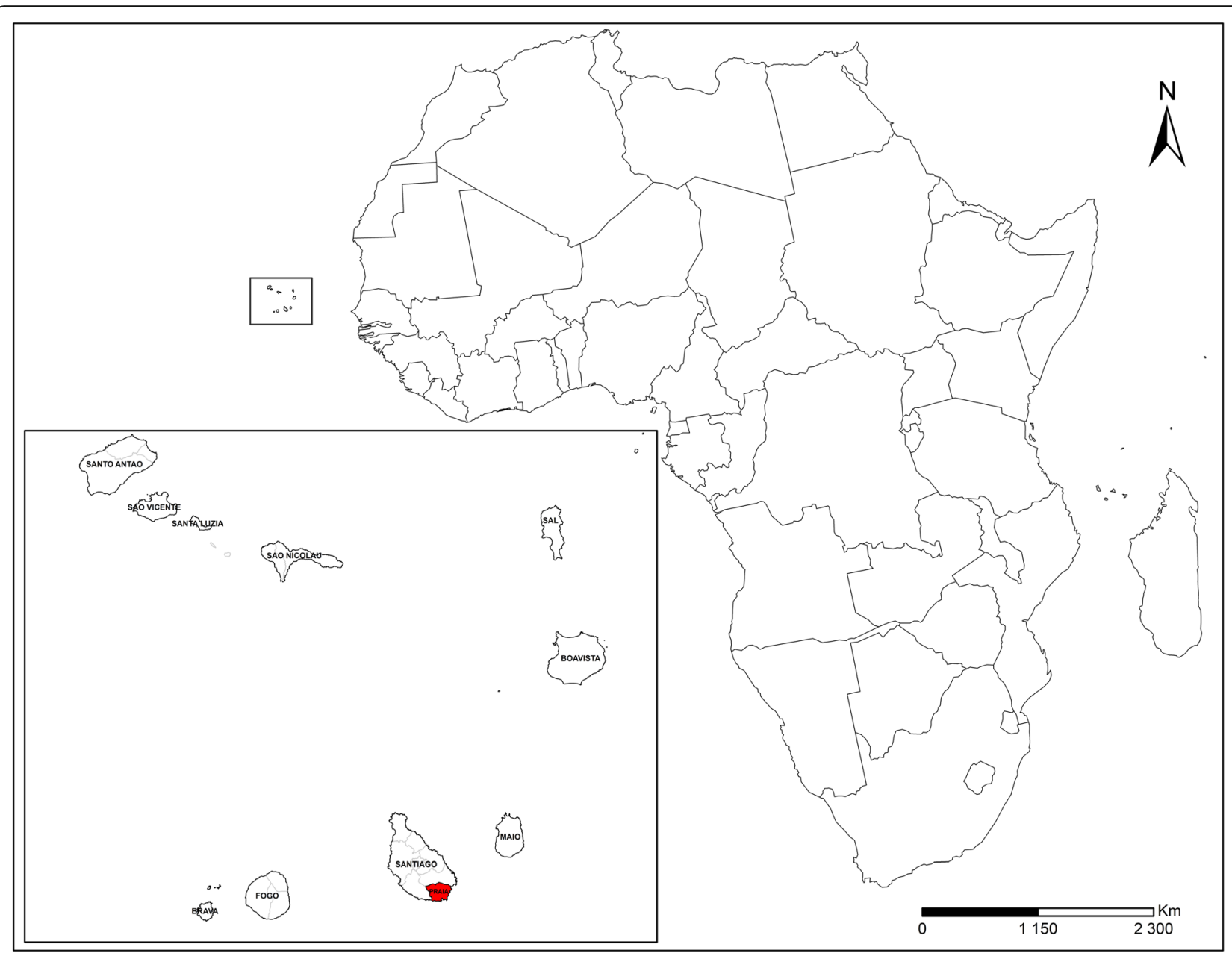

Fig. 1 Location of the Cabo Verde islands

rarely surpassing $32^{\circ} \mathrm{C}$ and the minimum hardly ever being lower than $18^{\circ} \mathrm{C}$ [23].

The municipality of Praia has recently recorded a high population growth rate of approximately $62 \%$ from 2000 to 2017 . Almost $35.9 \%$ of the capital resident population come from other countries, with only $4.9 \%$ originating from the other islands of the archipelago. Seventy-two and $62 \%$ of the 44,079 households in Praia have access to electricity and piped water, respectively. Furthermore, $85.2 \%$ of the population have access to the sewage network. Approximately $28.1 \%$ of the population is classified as poor with a low level of education [24].

Praia is the principal malaria focus for Cabo Verde with $90 \%$ of indigenous cases in recent years from 2010 to 2016 [10]. For malaria control, the health delegation has a vector control team that goes to the field daily and performs the vector control activities, namely, identifying breeding sites, collecting identification information using a form, treating the larvae and surveying the municipality. In the study, all larval surveys were carried out at breeding sites, which were single pools of water with Anopheles present. The larval surveys had been done initially as a preventive activity, but with the notification of a malaria case, they were identified as part of the response to malaria cases. Data from January to December 2017 were used.

\section{Data collection}

One of the greatest challenges for the control of malaria in low-transmission areas is its mapping, due to the concentration in hotspots and hot pops. In Cabo Verde, malaria notification is mandatory as part of the elimination programme. Therefore, all new cases are immediately reported and aggregated weekly in order to detect potential outbreaks immediately and to react in a timely manner. The individual notification form included personal information, residential address and supplementary information, which enabled the classification of each case as indigenous or imported. The data used in this study were retrieved from the National Malaria Control Programme (NMCP) and the National Surveillance Service, both operated under the authority of the 
Ministry of the Health $(\mathrm{MoH})$ and Social Security. Individual data for each malaria case recorded from January to December 2017 were crosschecked and curated for completeness of the recorded information on the disease.

In order to infer the potential role of climatic factors, risk and transmission, meteorological data, which included monthly mean temperature, relative humidity, wind speed and rainfall, were obtained from the National Institute of Meteorology and Geophysics of Cabo Verde.

\section{Data analysis}

\section{Epidemiological analysis}

The incidence of malaria by sex and age was estimated as the total number of confirmed cases in each group per 1000 inhabitants and was mapped by area for different regions of Praia using a choropleth map.

\section{Analysis of spatial autocorrelation and spatial distribution of malaria cases}

To analyse the patterns of malaria and the spatial distribution of cases in Praia, a spatial autocorrelation analysis was performed using the Cluster and Outlier Analysis (Anselin Local Moran's I) to identify statistically significant access points, cold points and spatial outliers and to estimate the spatial pattern of malaria cases [25]. This statistical test evaluates adjacent positions. A strong positive spatial autocorrelation is determined when the surrounding incidence of disease over the entire study area has analogous values. If the surrounding values are very different, the statistics point out a strong negative spatial autocorrelation. The value of Moran's $I$ Index varies between -1 and 1 . The $Z$ value estimates whether the observed clustering/dispersing is statistically significant [26, 27]. Local Moran's $I$ Statistics was defined as follows:

$$
I_{i}(d)=\left(x_{i}-\bar{x}\right) \sum_{j=1}^{n} w_{i j}(d)(x-\bar{x}), j \neq 1
$$

where $\bar{x}$ was the annual incidence of $P$. falciparum cases in the area, $x_{i}$ and $x_{j}$ were the annual incidence of $P$. falciparum cases at district $i$ and $j$, respectively, and $w_{i j}$ was the spatial weight matrix based on the defined distance lags between area $i$ and area $j$, where $w_{i j}(d)=1$ when neighbourhoods $i$ and $j$ were adjacent and 0 when $i$ and $j$ were not adjacent.

The Cluster-Outlier (CO) type field differentiates between a statistically significant $(p<0.01)$ cluster of high values (high-high), a cluster of low values (low-low), an outlier in which a high value is surrounded primarily by low values (high-low), and an outlier in which a low value is surrounded primarily by high values (low-high). A positive value for ' $P$ indicates that the adjacent districts are bounded by $P$. falciparum incidences with similar values. Such a feature is a cluster. A negative value for $I$ indicates that the adjacent area is delimited by $P$. falciparum incidences with different values. Such a feature is an outlier. The Local Moran's I can only be inferred with an estimated $Z$-score or $p$ value. A 99\% level of significance $(p<0.01)$ was used to designate important clusters of local autocorrelations [26, 27].

The patterns of malaria and spatially distributed cases were analysed for incidence (cases number/1000 population) $[25,26]$. Statistically significant access points, cold points and spatial outliers were identified using statistics based on the inverse-distance relationship in which neighbours had a greater influence on calculations for a destination than distant locations and where distance was measured as a straight line between the two using Euclidean distance. The expected and observed index values were compared and the spatial correlation variance of malaria cases was determined using the $Z$-score. The $p$ values were calculated to assess the significant differences of scores, and the pattern of spatial distribution was mapped to visualise the clusters of hotspots and cold areas.

\section{Analysis of risk factors}

Potential risk factors implicated in the increase of malaria cases during the 2017 outbreak were assessed through a linear relationship analysis between the number of malaria cases and the presence of vector breeding sites using a multiple regression and a Pearson correlation. A temporal cluster analysis was used to detect which climatic risk factors most correlated with malaria cases throughout the year by integrating explicative variables such as the average temperature $\left({ }^{\circ} \mathrm{C}\right)$, mean relative humidity $(\%)$, average wind speed $(\mathrm{m} / \mathrm{s})$, and total rainfall $(\mathrm{mm})$ in the model.

\section{Results \\ Epidemiological characteristics}

A total of 446 cases of malaria were reported in Cabo Verde in 2017. Among these cases, 423 (94.8\%) were indigenous cases from Praia, the capital of the country. The other 23 (5.2\%) cases were imported, with infections being acquired outside of the country. During the same period, two malaria-related deaths were recorded, one in São Vicente and the other in Praia. Furthermore, 17 patients experienced two episodes of relapse while one patient experienced three episodes of relapse during the study period (Table 1 ).

Based on the WHO case classifications, which define imported cases as infections acquired outside of the country and indigenous cases as infections contracted locally with no evidence of importation, all the cases reported during the outbreak were correctly classified [4]. Praia, the capital city, recorded 423 cases (96.6\%) followed by São Vicente with 7 cases (1.6\%). All the other six municipalities 
Table 1 Number of malaria cases in Cabo Verde in 2017

\begin{tabular}{lll}
\hline & No. of cases & Percentage (\%) \\
\hline Indigenous & 423 & 94.8 \\
Imported & 23 & 5.2 \\
TOTAL & 446 & 100 \\
Death & 2 & 0.4 \\
Relapsed 2X & 17 & 3.8 \\
Relapsed 3x & 1 & 0.2 \\
\hline
\end{tabular}

had only one case each $(0.2 \%)$ (Table 2 ). All of the indigenous and all the imported cases from African countries were identified as $P$. falciparum infections, while the single imported case from Brazil was a P. vivax infection. Notably, analysis of the patient travel histories showed that all the indigenous cases reported by the other municipalities originated from the capital city, Praia.

\section{Indigenous cases}

Further analysis of the indigenous cases recorded in Praia revealed that men were the most affected group $(69.3 \%, n=293)$. With a total incidence of $2.7 / 1000$, the disease incidence was significantly higher among males than in females (3.7 and 1.7/1000, respectively). Although all age groups were affected by the outbreak (Table 3), young adults of 20-24 years of age were at highest risk, accounting for $13.7 \%(n=58)$ of the total cases. The incidence was higher for the 50-54 age group and lower for the 0-4 age group, being 6.3 and $0.8 / 1000$, respectively.

Further analysis of the locally acquired cases revealed a temporal variation for malaria infection in Praia, mostly marked by a seasonal pattern. Indeed, only a small number of cases (five males and two female cases) were reported during the first semester of the year (January-June). Most of the cases were acquired between July and October, ranging from 44 to 147 cases. Disease incidence decreased towards the end of the year with 15 cases in November and 5 in December (Fig. 2).

\section{Imported cases}

Investigation into the source of the imported malaria cases revealed that they originated mainly from the

Table 2 Number of malaria cases in Cabo Verde by municipality and origin

\begin{tabular}{llll}
\hline Municipalities & Indigenous & Imported & Percentage (\%) \\
\hline Praia & 423 & 13 & 97.8 \\
São Vicente & 0 & 7 & 1.6 \\
Santa Catarina & 0 & 1 & 0.2 \\
Porto Novo & 0 & 1 & 0.2 \\
Sal & 0 & 1 & 0.2 \\
Total & 423 & 23 & 100 \\
\hline
\end{tabular}

Table 3 Distribution of the malaria indigenous cases by sex and age in Praia in 2017

\begin{tabular}{|c|c|c|c|c|}
\hline & Population & $\begin{array}{l}\text { No. of malaria } \\
\text { infections }\end{array}$ & Percentage (\%) & Incidence (/1000) \\
\hline \multicolumn{5}{|l|}{ Sex } \\
\hline M & 78,709 & 293 & 69.3 & 3.7 \\
\hline $\mathrm{F}$ & 80,318 & 130 & 30.7 & 1.7 \\
\hline \multicolumn{5}{|l|}{ Age } \\
\hline $0-4$ & 17,165 & 13 & 3.1 & 0.8 \\
\hline $5-9$ & 16,378 & 22 & 5.2 & 1.3 \\
\hline $10-14$ & 16,283 & 33 & 7.8 & 2.0 \\
\hline $15-19$ & 17,717 & 28 & 6.6 & 1.6 \\
\hline $20-24$ & 18,739 & 58 & 13.7 & 3.1 \\
\hline $25-29$ & 16,573 & 50 & 11.8 & 3.0 \\
\hline $30-34$ & 13,201 & 36 & 8.5 & 2.7 \\
\hline $35-39$ & 9560 & 37 & 8.7 & 3.9 \\
\hline $40-44$ & 8926 & 45 & 10.6 & 5.0 \\
\hline $45-49$ & 7813 & 20 & 4.7 & 2.6 \\
\hline $50-54$ & 5729 & 36 & 8.5 & 6.3 \\
\hline $55-59$ & 3553 & 20 & 4.7 & 5.6 \\
\hline $60-64$ & 1619 & 6 & 1.4 & 3.7 \\
\hline $65+$ & 5803 & 12 & 2.8 & 2.1 \\
\hline NA & & 7 & 1.7 & \\
\hline Total & 159,057 & 423 & 100 & 2.7 \\
\hline
\end{tabular}

NA data not available

African continent, mostly from the Portuguese speaking countries of Angola and Guinea Bissau (21.7\% each). The non-Portuguese speaking countries implicated were Senegal, Nigeria, and Guinea Conakry with five imported cases each. The remaining cases consisted of four $P$. falciparum infections from Benin, Ivory Coast, Burkina Faso and Ghana (one case each), and the single P. vivax infection imported from Brazil (Table 4).

\section{Spatial and temporal analysis of malaria case distribution in Cabo Verde in 2017}

The spatial analysis indicates a positive spatial autocorrelation and clustering (Moran's $I$ value $=0.22 ; Z$-score $=$ $4.15 ; p<0.05)$ of malaria cases with three main patterns (Fig. 3).

Notably, the spatial distribution of cases revealed that in Praia, the highest incidence of malaria was concentrated in the centre of the city, where a cluster of high-to-high incidence was identified within the neighbourhoods of Varzea, Fazenda/Sucupira, Tahiti, Lem Cachorro, Paiol, Achadinha Pires, Achadinha, and Ponta de Agua. In the western part of the city, the Simão Ribeiro and Envi Zone concentrated a cluster of low incidence. The rest of the area in Praia did not display any significant pattern (Figs. 3 and 4). 


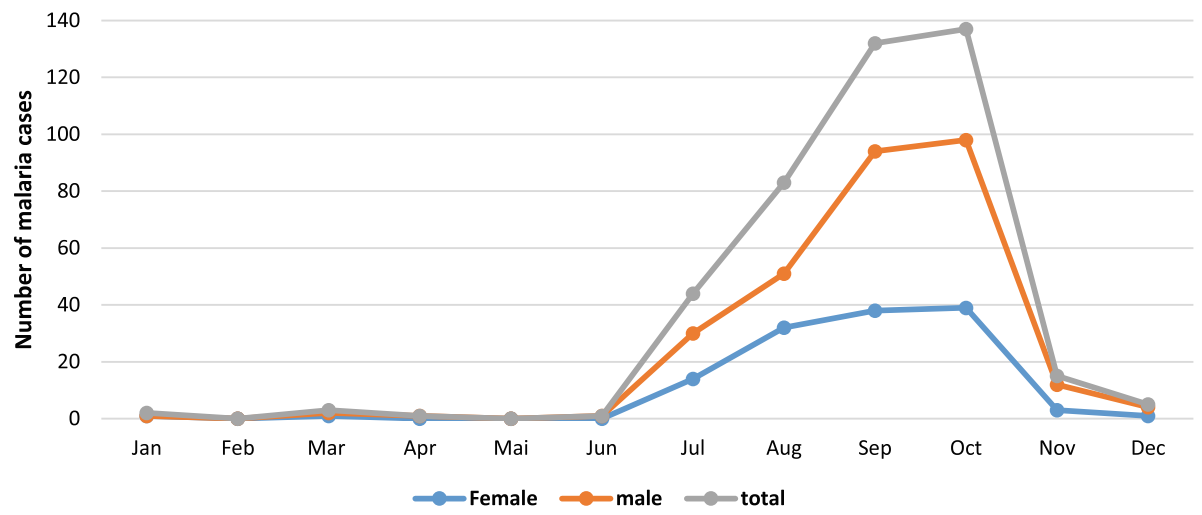

Fig. 2 Temporal variation of malaria among males and females in Cabo Verde in 2017

Ecological and environmental risk factors associated with Malaria in Praia in 2017

Regression analysis allows for the modelling, examining and exploring of spatial relationships and helps to explain the factors behind the spatial patterns observed. This analysis can show why cases of malaria are higher in one neighbourhood than another, or which factors justify these cases of malaria in the modelling of spatial relationships.

Figure 5 shows the association between the number of malaria cases in Praia in 2017 and the total number of positive breeding sites identified in neighbourhoods. We found a moderate positive linear correlation between malaria case occurrence and the breeding sites for the main malaria vector, An. gambiae s.l (Fig. 6).

The multiple linear regression analysis performed to assess the potential relationship between malaria cases and the meteorological variables, such as the mean temperature $\left({ }^{\circ} \mathrm{C}\right)$, mean relative humidity (\%), average wind speed $(\mathrm{m} / \mathrm{s})$ and total rainfall $(\mathrm{mm})$, has shown that the $69.9 \%$ variation in malaria cases during the year

Table 4 Origin of imported malaria cases in 2017

\begin{tabular}{lll}
\hline Imported & No. of cases & Percentage (\%) \\
\hline Angola & 5 & 21.7 \\
Guinea Bissau & 5 & 21.7 \\
Senegal & 2 & 8.7 \\
Guinea Conakry & 2 & 8.7 \\
Nigeria & 2 & 8.7 \\
NA & 2 & 8.7 \\
Benin & 1 & 4.3 \\
Ivory Coast & 1 & 4.3 \\
Burkina Faso & 1 & 4.3 \\
Ghana & 1 & 4.3 \\
Brazil & 1 & 4.3 \\
Total & 23 & 100
\end{tabular}

NA data not available for Praia is explained by the model with a highly positive linear correlation $(r=0.84)$. The mean temperature shows a strong relationship with malaria occurrence $(r=0.79)$ in Praia. Both the mean relative humidity $(r=0.39)$ and the total rainfall $(r=0.28)$ were moderately associated with the risk of malaria infection. Conversely, the average wind speed was negatively correlated to malaria $(r=-0.54)$. Figure 7 shows this correlation during the year.

The graph shown above illustrates the evolution of malaria cases and environmental data. The number of malaria cases increased after the first precipitation in July. Although there was no more rain in the following months, it seems that the precipitation in July was sufficient to increase the number of cases in the following months with a peak in October and a decrease in November and December. The data show a plateau of malaria cases just as the rains end.

After each case was notified by the health structure (hospital or health centre), a reactive response was initiated by the health delegation, and a team, including the epidemiological and entomological survey, allowed for a good classification of the cases. The reactive research into malaria after the index case, including the use of the rapid diagnostic test in the family and neighbour's houses, the IRS, community mobilisation actions and other activities, the capacity of a good technician to manage cases, clinical and lab diagnosis, may all contribute to the reduction of cases and low mortality. Figure 8 shows the level of responsiveness following the number of cases reported based on the level of IRS and RDT.

\section{Discussion}

\section{Epidemiology of malaria in Cabo Verde}

This study investigated the epidemiological and spatiotemporal outbreak characteristics and risk factors of malaria for Praia, Cabo Verde, in 2017, as the country is in the pre-elimination stage [8]. Malaria elimination in Cabo Verde, which is set to be achieved by 2020, is 
significant for the health and economic development of Cabo Verde [5].

Studies show that progress in shrinking the malaria map with a focus on vector control, parasite incidence and other interventions, can maximise the impact on the control and elimination of the disease [13-18, 28]. In Cabo Verde, the mapping of malaria data remains a challenge. In recent years, the National Malaria Control Programme (NMCP) in partnership with national and international institutions has taken the first steps in this direction. With the outbreak of malaria in 2017, data on case location and breeding site identification began to be collected.

The indigenous cases in 2017 were centred in Praia, and a few imported cases were registered in other municipalities. There was a substantial increase in cases compared to records from recent years [10]. Praia continues to be a focus for malaria in the country, with the epidemiological and ecological factors necessary for malaria transmission [29], and for the last 2 years (2016-2017), all indigenous cases originated there [10, 27].
The results demonstrate that malaria transmission varies due to gender and age in the country. The high incidence rate observed in males in comparison with females might be due to different exposure rates or other behavioural risk factors. Similar studies have demonstrated the disproportionate burden by gender, with males being more affected, probably due to greater mobility and work-related activity in fields and risky areas [30,31]. There are no studies on the profile of malaria patients in Cabo Verde, but the data on the notification forms from the last years indicate that men are more affected, particularly those who work as security, guards, the homeless and construction or agricultural workers. This finding is in contrast to those obtained in other countries in the African region, such as Mauritania, Senegal and Central Vietnam, where malaria affects mostly women and children under 5 years of age [32-34].

In Africa, malaria normally affects all age groups of the population in areas with unstable malaria transmission [33, 35-38]. In this study, the group aged 20-24

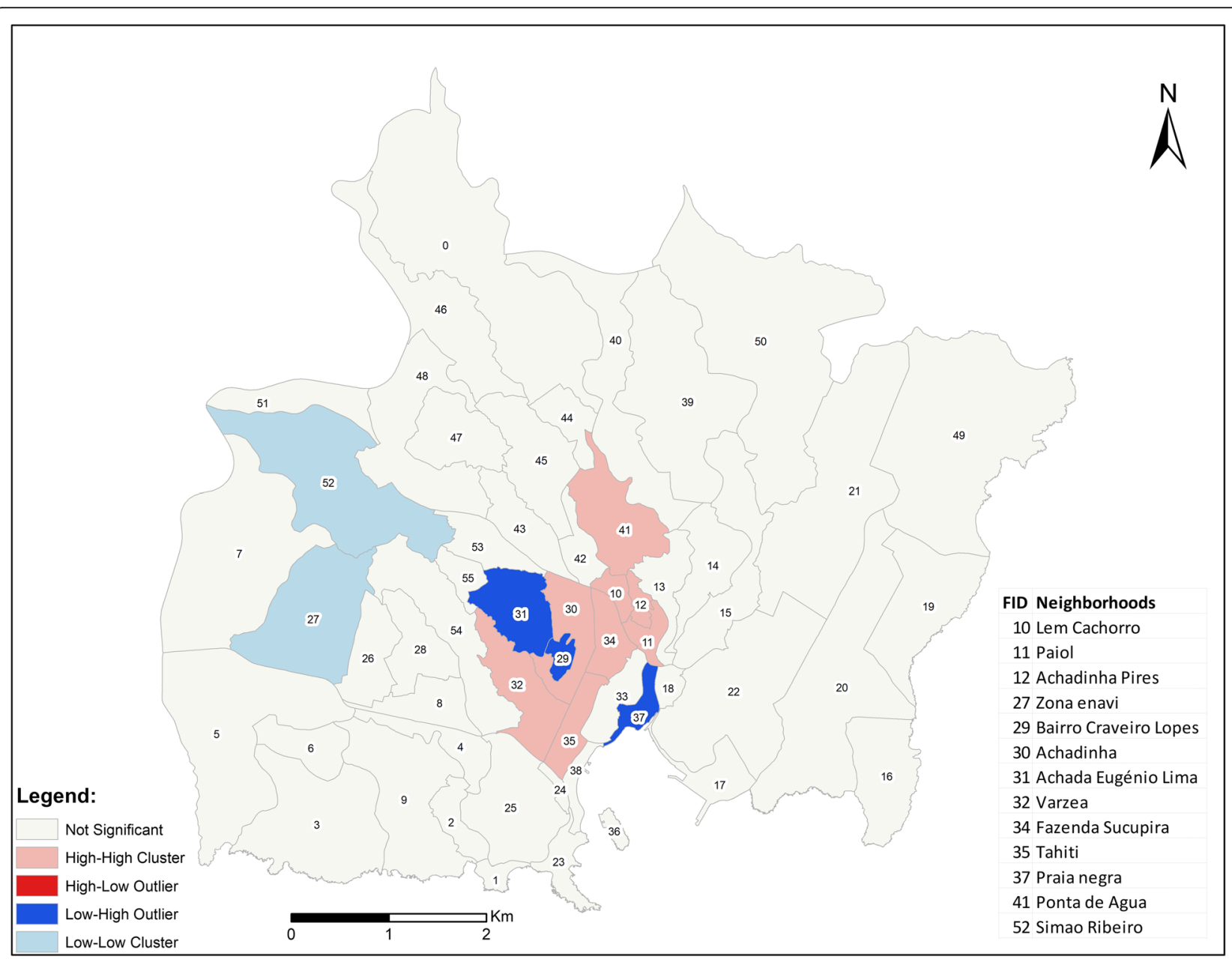

Fig. 3 Spatial autocorrelation of malaria cases in Praia in 2017 


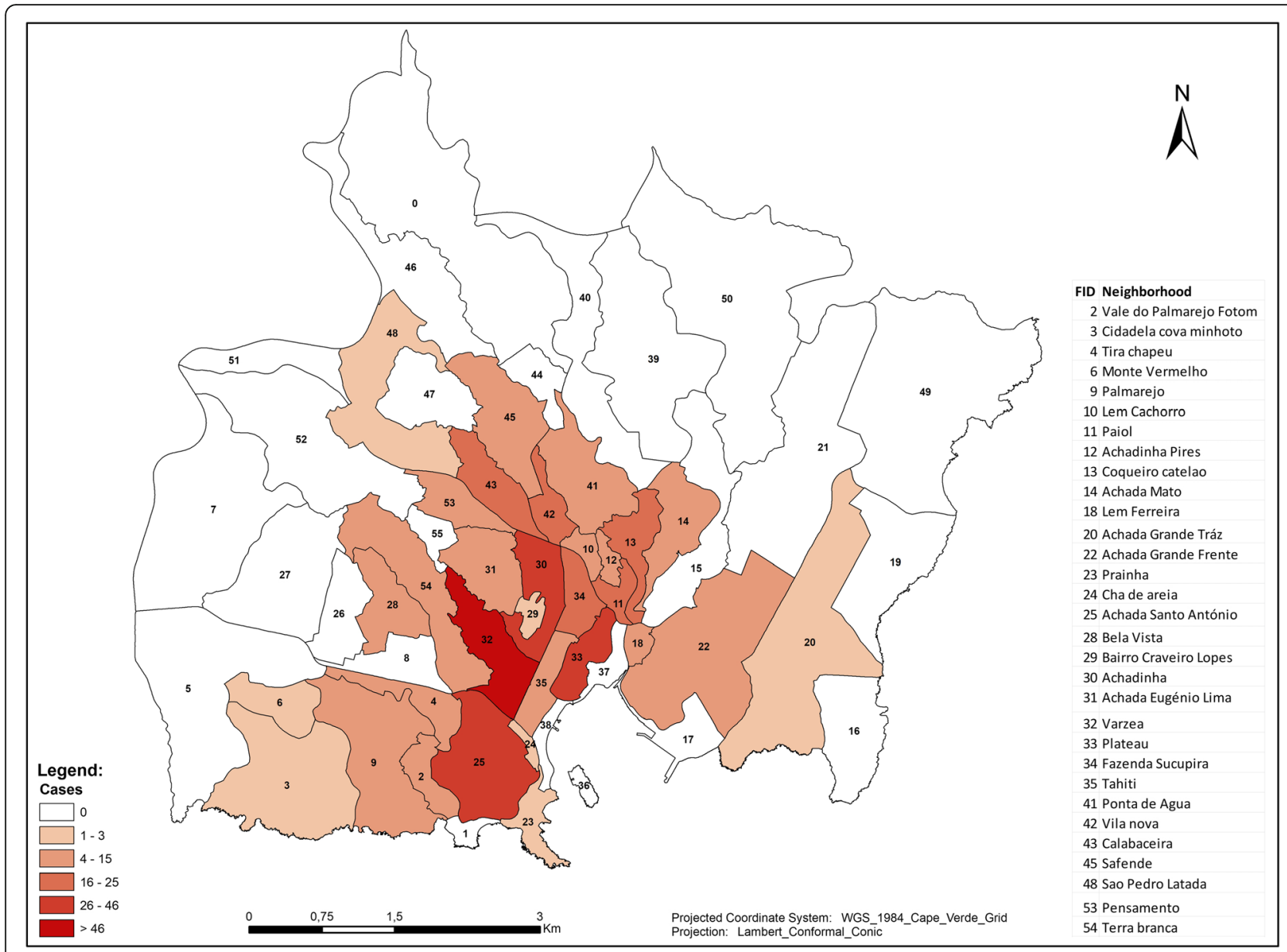

Fig. 4 Cases of malaria in Praia, Cabo Verde, 2017

and 25-29 years old had the highest number of cases (58 and 50 cases, respectively), and the highest incidence rate was in the group aged 50-54 years (6.4/1.000 habitants).

The reported number of imported cases in 2017 was similar to that in recent years [10]. This finding is similar to that obtained in other countries in Africa, such as Reunion Island, where a considerable number of imported cases are from African countries [39], or Sri Lanka [40], a country in the process of malaria elimination with cases from South Asia, India and

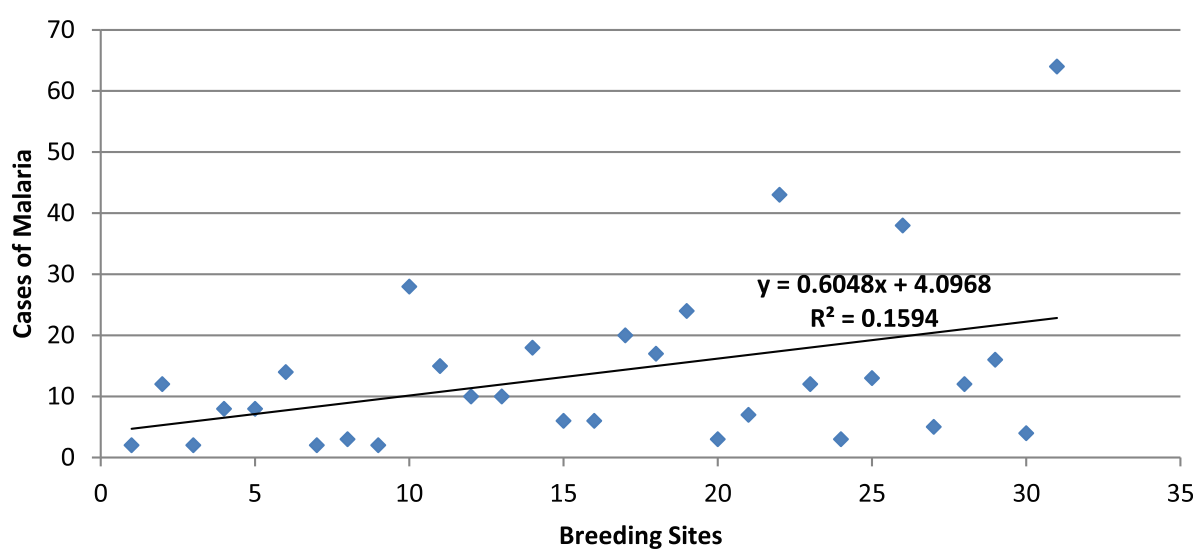

Fig. 5 Association between positive breeding sites and cases of malaria in Praia, Cabo Verde, 2017 


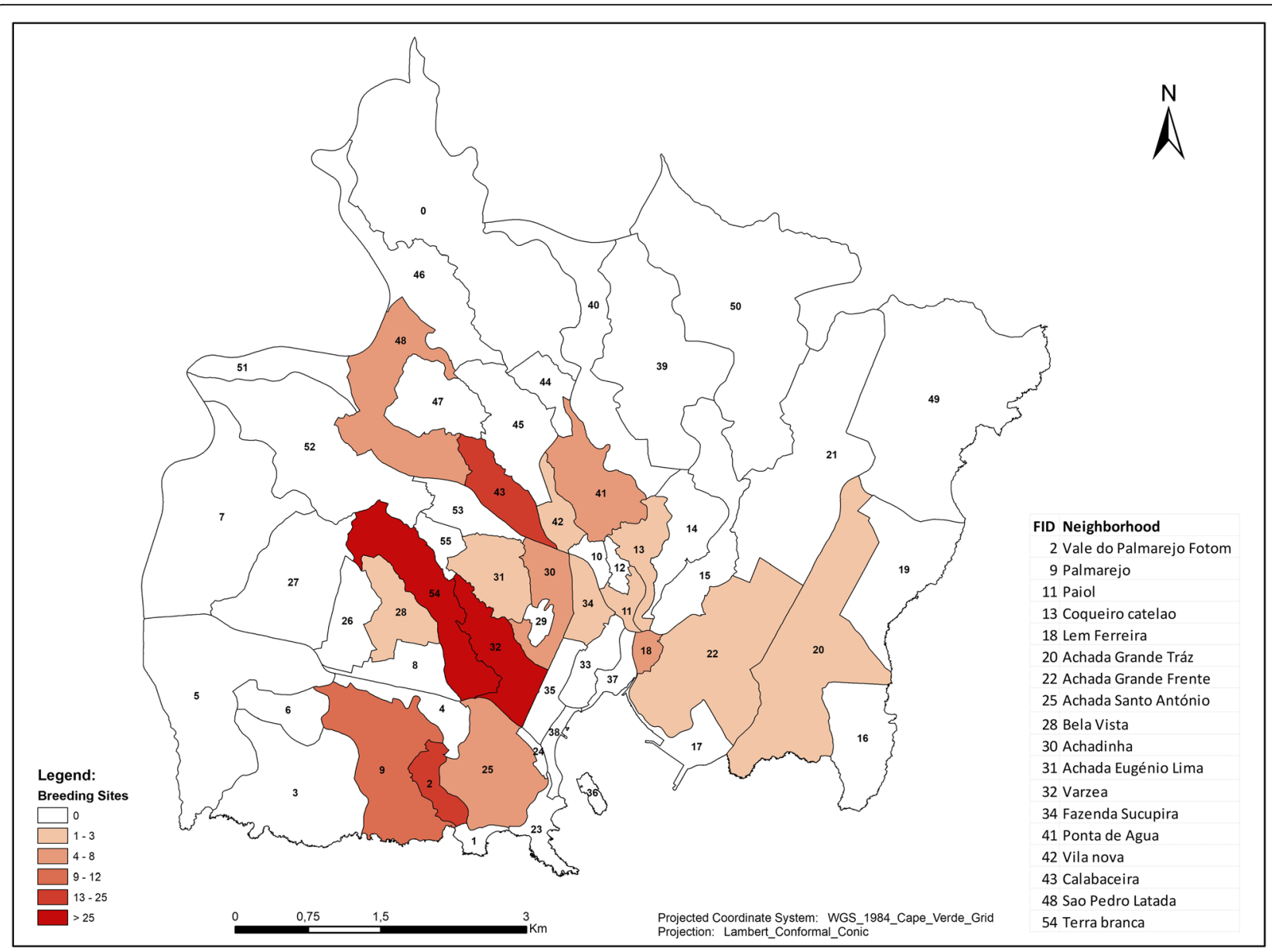

Fig. 6 Variation of breeding sites by area in Praia, Cabo Verde, 2017

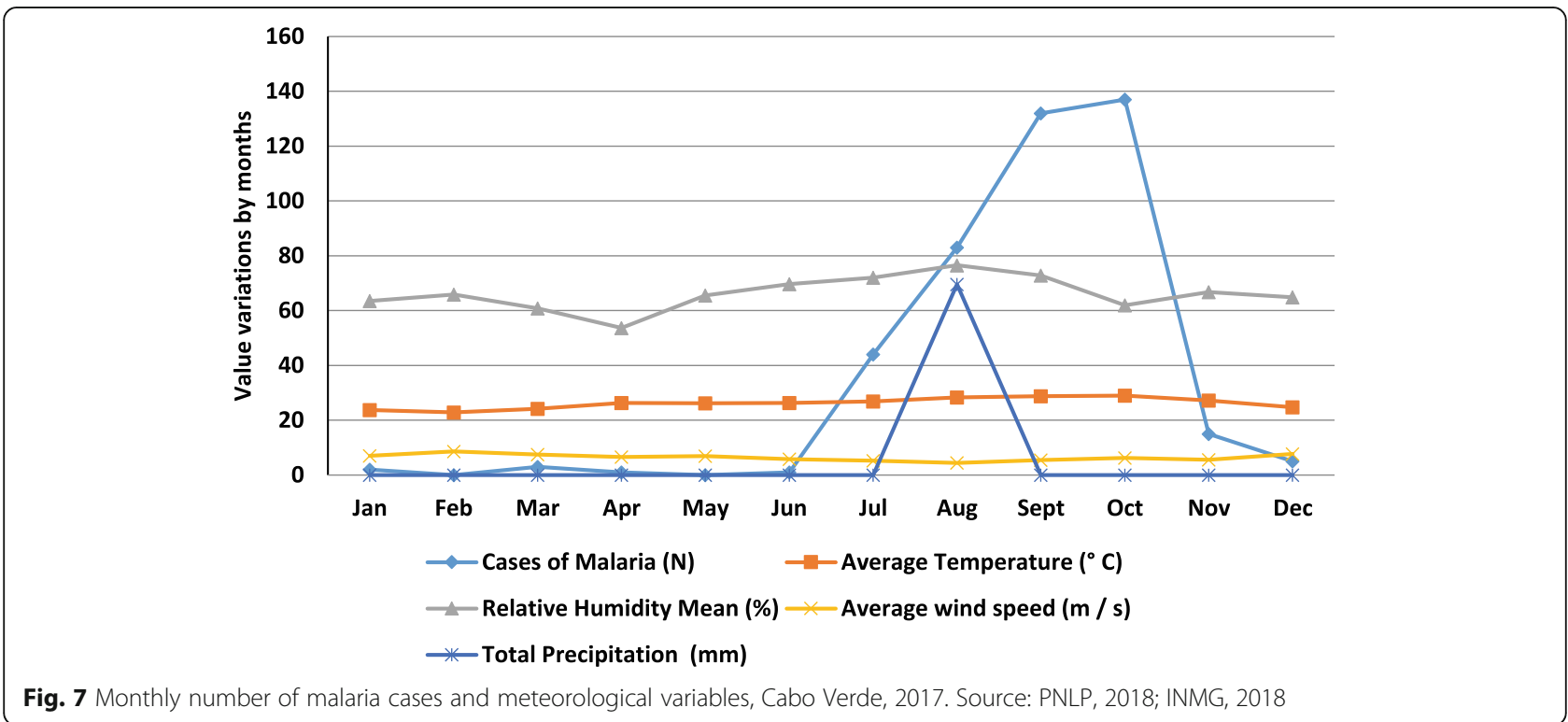




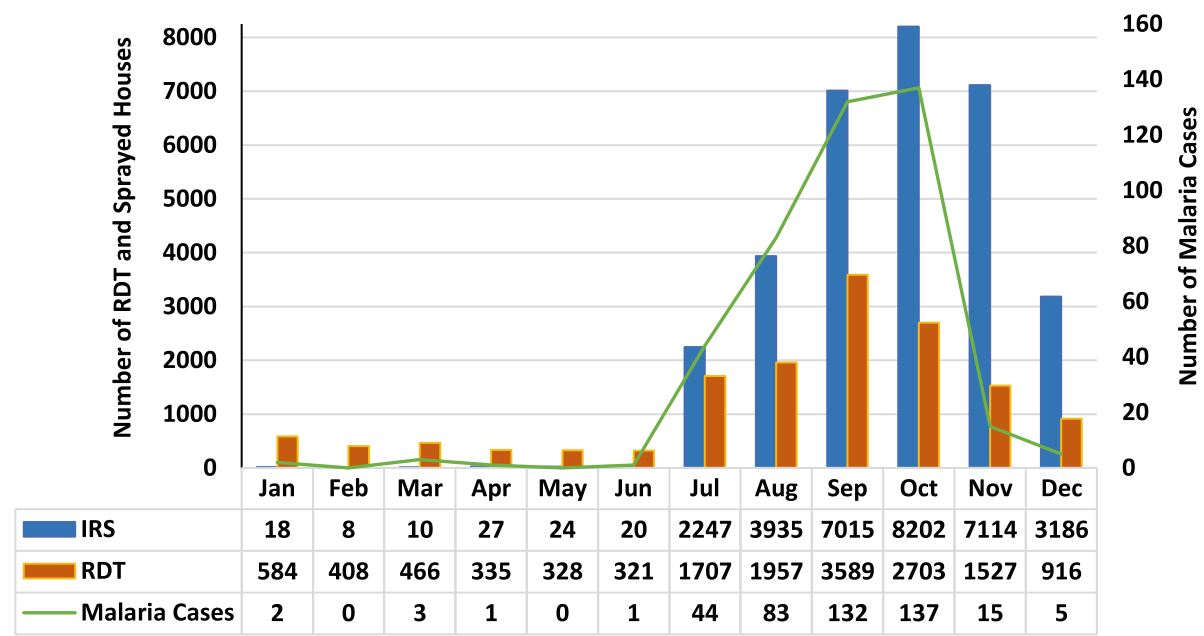

Fig. 8 Number of rapid diagnostic test (RDT) and indoor residual sprayed (IRS) houses in Praia, Cabo Verde, during malaria outbreak 2017

considerable numbers from Africa. However, the number of indigenous cases was more than 18 times higher than for imported cases.

The illness most frequently diagnosed in travellers all over the world is malaria [41], and Cabo Verde continues to receive cases of malaria from other countries, especially from the Lusophone world (Angola and Guinea Bissau) and from the West Africa region. This continuous history of imported cases presents a challenge for the country that in the context of elimination, Cabo Verde needs to have an excellent surveillance and response service, including information systems to allow for the identification, tracking, classification and response for all cases. Imported cases need to be followed and shown not to generate secondary cases, which are transmitted locally (introduced cases) [28].

The seasonality of cases in 2017 for Cabo Verde is similar to the previous years (2010-2016) [10] and to some others Sahelian countries [42, 43]. In these areas with seasonal malaria transmission, the incidence rate is presumed to be near zero in the dry season. During the first semester of the year (January-June), only 11 cases were reported in the country, with 7 of these being indigenous, representing only $2.5 \%$ of the total cases. All other cases were in the second semester of the year (July-December), the rainy period of the country, when the weather is especially hot and humid. The peak period for malaria cases in Cabo Verde differs from other countries in the elimination stage, such as Swaziland where there is a high prevalence in December to February [44].

The good organisation of health services in case management has made it possible to provide the best care for the hospitalised and treated cases, as well as for the response to cases, including the availability of RDT and IRS. This management has resulted in only two deaths, despite the high number of cases $(0.2 \%$ mortality rate).
One of the fatal cases was an imported case from Sao Vicente, and the other was a homeless case from Praia.

The high incidence of malaria is related to the complex geography and environmental conditions, such as the weather and climate [44, 45]. The hot and humid conditions are appropriate for breeding Anopheles [46], and the epidemiological characteristics of malaria in Cabo Verde showed an obvious seasonal pattern and demographic distribution that could be correlated with the high density and the capacity of the vectors to transmit the disease. The outbreak season for malaria in the country is during the summer, as shown in Fig. 2. Malaria incidence increased rapidly from July to October and decreased in November.

The areas with higher numbers of cases were identified as having high numbers of positive breeding sites. The results show a moderately positive linear correlation between the malaria cases in Praia and positive breeding sites (Fig. 5). This means that other factors had a significant contribution to the outbreaks of malaria in Praia. The results of the cluster map showed a high-high cluster of malaria cases in the centre of the city, encompassing the neighbourhoods of Várzea, Chã de Areia, Fazenda, Achadinha, Paiol and Lém Ferreira, during the outbreak. As mentioned before, several factors could explain this high-high cluster, as environmental, health and economic conditions have been found in studies conducted from others regions $[44,47,48]$.

Environmental conditions and climate variables play an important role in the dynamics, distribution, and transmission of malaria and other vector-borne diseases. Generally, annual cumulative rainfall and annual average temperature were positively associated with the malaria incidence rate $[49,50]$. Rainfall is critical in providing a suitable habitat and consequently has a significant impact on the survival rate of Anopheles mosquitoes. In 
2017, the presence of breeding sites had a very weak correlation with the incidence of cases, which means that other determinants had a major impact on the malaria cases. Breeding sites as a result of low rainfall included the presence of permanent water troughs, agricultural areas, wells and other permanent ponds in the floodplain and surrounding areas, were principally identified during the malaria responses in Praia (Fig. 7). The fact that the early cases occurred in the Tahiti/ Ponta Belém zone, peripheral to the areas of the large Sucupira market, where there is a large influx of population due to informal commerce from endemic African countries, could explain the increase and expansion of cases to other neighbourhoods of Praia and other municipalities of the Santiago island.

Temperature is a key driver that affects the essential processes of mosquito biology and parasite life cycle [51]. Temperature determines transmission intensity, including mosquito development rate, biting rate and survival of the parasite within the mosquito $[50,52]$. In this study, the average annual temperature shows a strong positive correlation with malaria cases in Praia. A study of malaria distribution in ten West African countries (Benin, Burkina Faso, Côte d'Ivoire, Gambia, Ghana, Liberia, Mali, Senegal, Sierra Leone and Togo) during the period of 1996-2006 had similar results, where the two most important climate factors were found to be the average annual temperature and the total annual precipitation [45]. Other recent studies had similar results [52,53]. It is important to note that, in cases where temperature extremes set boundaries on vector distributions, climate change might alter the range (in altitude or latitude) of favourable environmental conditions for malaria vectors and parasites. We noted that the greatest effect of climate change on malaria is likely to be observed at a temperature equal to $25^{\circ} \mathrm{C}$, corresponding to the favourable conditions for disease transmission [52].

There are temporal variations in the incidence of malaria that may be related to variations in climate and other local environmental risk factors [54, 55]. In this study, most malaria occurs from July to November with an increase of cases in September and a peak in October, immediately after the rains in August.

In addition to the direct influence of temperature on malaria incidence based on the biology of vectors and parasites, the precipitation patterns could also have effects on malaria in Africa [54-57]. We can see it in Cabo Verde, despite higher rainfall values in the past, that the number of cases of malaria was lower [10]. In this study, the pluviometry $(\mathrm{mm})$ had a moderately positive correlation with cases of malaria. Of the other two factors analysed, the relative humidity showed a strong positive correlation and the average wind speed had a strong negative correlation, since wind has an impact on mosquito dispersion.
Climate change has been related to a rise in approximately $6 \%$ of malaria cases during 2000 for middle-income countries [56-58]. Environmental changes such as rainfall and temperature have been associated with other diseases like non-cholera diarrhoea, [59] visceral leishmaniasis [60] and others diseases. People in tropical areas and with lower educational levels are the most vulnerable to the effect of these factors.

The expected increases in temperature, changes in precipitation patterns, and increased flooding and drainage are important issues in developing and archipelagic countries, like Cabo Verde [61-63]. The impact of these factors on water-borne and vector-borne diseases is of particular relevance in terms of policies and public health strategies, regarding the prevention of these diseases. Further studies considering multiple areas and biological models of mosquito development are needed to improve detection of temperature effects on malaria transmission and the relative contribution of these risk factors.

\section{Conclusions}

This study was conducted to analyse the cases of malaria in Cabo Verde during the outbreak in 2017 in Praia. Men and people $>20$ years old were more affected by the disease in the country. Imported cases were from the Lusophone world, and one case of $P$. vivax from Brazil was identified. The reporting of cases had the same epidemiological tendencies, which were recorded mainly between July and October. Cabo Verde has an excellent case management programme, which resulted in a reduction in the mortality rate.

Measures on the effect of environmental factors for malaria showed a strong positive correlation with temperature and relative humidity, a moderately positive correlation with the pluviometry and a strong negative correlation with wind speed. Findings from this study shall help policy and decision makers in preventive measures for malaria control and to achieve the malaria elimination goal for this country. More studies are recommended to complete these results and elaborate on surveillance plans and activities to adequately achieve malaria elimination in the country.

\section{Abbreviations}

BWh: Hot desert climate; DDT: Dichlorodiphenyltrichloroethane; FID: Features identify; GDP: Gross domestic product; IRS: Indoor residual spraying; MoH: Ministry of Health; NMCP: National Malaria Control Programme; RDT: Rapid diagnostic test; WHO: World Health Organization

\section{Acknowledgements}

We are grateful to the healthcare workers in the health centres, delegation centre and Agostinho Neto Hospital in Praia, which worked tirelessly on case management and data reporting. We are also grateful for the colleagues of the Epidemiological Surveillance Service and NMCP in the MoH for the compilation and availability of the data. We thank the National Meteorological and Geophysical service for the availability of meteorological data for the city of Praia. 


\section{Funding}

Not applicable.

\section{Availability of data and materials}

The datasets used and/or analysed during the current study are available from the corresponding author with a reasonable request.

\section{Authors' contributions}

ADP conceived of the manuscript. ADP and AJBA prepared the data and mapped the data. ADP, AKD and EAN drafted the manuscript. ADP, AKD and EAN edited the manuscript. All authors read and approved the final manuscript.

\section{Ethics approval and consent to participate}

Not applicable.

\section{Consent for publication}

Not applicable.

\section{Competing interests}

The authors declare that they have no competing interests.

\section{Publisher's Note}

Springer Nature remains neutral with regard to jurisdictional claims in published maps and institutional affiliations.

\section{Author details}

'Ecole Doctorale des Sciences de la Vie, de la Santé et de l'Environnement (ED-SEV), Université Cheikh Anta Diop (UCAD) de Dakar, Dakar, Sénégal. 2Programa de Pré-Eliminação do Paludismo, CCS-SIDA, Ministério da Saúde e da Segurança Social, Praia, Cape Verde. ${ }^{3}$ Instituto Nacional de Gestão do Território, Praia, Cape Verde. ${ }^{4}$ Laboratoire d'Ecologie Vectorielle et Parasitaire, Faculté des Sciences et Techniques, Université Cheikh Anta Diop (UCAD) de Dakar, Dakar, Sénégal. ${ }^{5}$ Programa Nacional de Luta contra o Paludismo, Ministério da Saúde e da Segurança Social, Praia, Cape Verde. ${ }^{6}$ Delegacia de Saúde da Praia, Praia, Cape Verde. Institut de Santé et Développement, Université Cheikh Anta Diop (UCAD) de Dakar, Dakar, Sénégal. ${ }^{8}$ Aix Marseille Univ, IRD, AP-HM, MEPHI, IHU-Méditerranée Infection, Marseille, France.

Received: 5 September 2018 Accepted: 3 December 2018

Published online: 07 January 2019

\section{References}

1. WHO. World malaria report. Geneva: World Health Organization; 2017. p. 2017.

2. WHO. World malaria report. Geneva: World Health Organization; 2016. p. 2016.

3. WHO. World malaria report. Geneva: World Health Organization; 2012. p. 2012.

4. WHO. Malaria programme reviews: a manual for reviewing the performance of malaria control and elimination programmes. Geneva: World Health Organization; 2010. p. 2010

5. Ministério da Saúde. Política Nacional da Saúde de Cabo Verde; 2007.

6. Instituto Nacional da Estatística de Cabo Verde. Projecção Demográficas de Cabo Verde, 2010-2030. INE. Cabo Verde; 2013.

7. World Bank, World Development Indicators database; country profile; Cabo Verde; Available in: http://www.worldbank.org/en/country/caboverde/ overview.

8. MoH. Ministry of Health Cape Verde, the World Health Organization and the University of California, San Francisco. Eliminating malaria. Moving towards sustainable elimination in Cape Verde. Geneva: World Health Organization; 2012.

9. Meira M, Nogueira J, Simões T. Observações sobre sezonismo nas ilhas do Sal, Boa Vista e S. Nicolau (Cape Verde). Anais do Instituto de Medicina Tropical. 1947;4:213-38.

10. De Pina AJ, Niang AH, Andrade AJ, Dia AK, Moreira A, Faye O, Seck I. Achievement of malaria pre-elimination in Cape Verde according to the data collected from 2010 to 2016. Malaria J. 2018;17:236.

11. Ministério da Saúde. Protocolo de Tratamento do Paludismo. In: Cabo Verde; 2015

12. Ministério da Saúde. Manual de Luta Integrada de Vectores. Cabo Verde; 2015.
13. Kakmeni FM, Guimapi RY, Ndjomatchoua FT, Pedro SA, Mutunga J, Tonnang HE. Spatial panorama of malaria prevalence in Africa under climate change and interventions scenarios. Int J Health Geogr. 2018;17:2.

14. Palaniyandi M. The role of remote sensing and GIS for spatial prediction of vector-borne diseases transmission. Journal of Vector Borne Disease. 2012; 49(4):197-204.

15. Saxena R, Nagpal BN, Srivastava A, Gupta SK, Dash AP. Application of spatial technology in malaria research \& control: Some new insights. Indian J of Medical Research. 2009;130(2):125-32.

16. Zacarias $\mathrm{O}$, Andersson M. Spatial and temporal patterns of malaria incidence in Mozambique. Malaria J. 2011:10:189.

17. Riedel N, Vounatsou P, Miller J, Gosoniu L, Chizema-Kawesha E, Mukonka V, et al. Geographical patterns and predictors of malaria risk in Zambia: Bayesian geostatistical modelling of the 2006 Zambia national malaria indicator survey (ZMIS). Malaria J. 2010:9:37.

18. Bhatt S, Cameron E, Flaxman SR, Weiss DJ, Smith DL, Gething PW. 2017. Improved prediction accuracy for disease risk mapping using Gaussian process stacked generalization. J R Soc Interface. 2017;20170520:14.

19. Alegana VA, Atkinson PM, Lourenço C, Ruktanonchai NW, Bosco C, Erbach-Schoenberg $E$, et al. Advances in mapping malaria for elimination: fine resolution modelling of Plasmodium falciparum incidence. Sci Rep. 2016;6:29628.

20. Sinka ME, Bangs MJ, Manguin S, Rubio-Palis Y, Chareonviriyaphap T, Coetzee $M$, et al. A global map of dominant malaria vectors. Parasit Vectors. 2012;5:69.

21. Kang SY, Battle KE, Gibson HS, Ratsimbasoa A, Randrianarivelojosia M, Ramboarina S, et al. Spatio-temporal mapping of Madagascar's Malaria Indicator Survey results to assess Plasmodium falciparum endemicity trends between 2011 and 2016. BMC Med. 2018;16:71.

22. Ferguson HM, Dornhaus A, Beeche A, Borgemeister C, Gottlieb M, Mulla MS, et al. Ecology: a prerequisite for malaria elimination and eradication. PLoS Med. 2010;7(8):e1000303.

23. Climate-data.org, Clima: Praia; Available in: https://pt.climate-data.org/ location/555/, Accessed in June 2018

24. INE. Instituto Nacional da Estatística de Cabo Verde. Dados Estatísticos sobre a Cidade da Praia; 2018. p. 1937-2017.

25. ArcGIS Pro. Cluster and outlier analysis (Anselin Local Moran's I). Available in http://pro.arcgis.com/en/pro-app/tool-reference/spatial-statistics/cluster-andoutlier-analysis-anselin-local-moran-s.htm. Acessed in June 2018;

26. Bhunia GS, Siddiqui NA, Shit PK, Chatterjee N, Sanjay Kumar Sinha SK. Spatial clustering of Plasmodium falciparum in Bihar (India) from 2007 to 2015. Spat Inf Res. 2016. https://doi.org/10.1007/s41324-016-0061-7.

27. Lee J, Wong DW. Statistical analysis with ArcView GIS. United States of America: Wiley; 2001.

28. WHO. A framework for malaria elimination. Geneva: World Health Organization; 2017. p. 2017.

29. Feachem RG, Phillips AA, Hwang J, Cotter C, Wielgosz B, Greenwood BM, et al. Shrinking the malaria map: progress and prospects. Lancet. 2010;376: 1566-78.

30. PNLP. Relatório de Actividades do Paludismo, 2017. Ministério da Saúde: Programa Nacional de Luta contra o Paludismo; 2018. p. 1-25.

31. Yeshiwondim AK, Gopal S, Hailemariam AT, Dengela DO, Patel HP. Spatial analysis of malaria incidence at the village level in areas with unstable transmission in Ethiopia. Int J Health Geogr. 2009;8:5.

32. Parker DM, Tripura R, Peto TJ, Maude RJ, Nguon C, Chalk J, et al. A multilevel spatial analysis of clinical malaria and subclinical Plasmodium infections in Pailin Province, Cambodia. Heliyon. 2017;3(11):e00447.

33. Moukah $\mathrm{MO}, \mathrm{Ba} \mathrm{O}, \mathrm{Ba} \mathrm{H}$, Khairy ML, Faye O, Bogreau H, et al. Malaria in three epidemiological strata in Mauritania. Malar J. 2016;15:204.

34. Bannister-Tyrrell M, Xa NX, Kattenberg JH, Van NV, Dung VK, Hieu TM, et al. Micro-epidemiology of malaria in an elimination setting in Central Vietnam. Malar J. 2018;17:119.

35. Espié E, Sarr FD, Diop F, Faye J, Richard V, Tall A, Baldé AT. Spatio-temporal variations in malaria incidence in children less than 10 years old, Health District of Sokone, Senegal, 2010-2013. PLoS One. 2015;10(9):e0137737.

36. Kiszewski AE, Tekelehaimanot A. A review of the clinical and epidemiologic burdens of epidemic malaria. Am J Trop Med Hyg. 2004;71(Suppl 2):128-35.

37. Fantahun M, Alene GD. Burden of Diseases in Amhara Region, Ethiopia. Ethiop Med J. 2004;42(3):165-72.

38. Gerritsen AM, Kruger P, van der LMFS, Grobusch MP. Malaria incidence in Limpopo Province, South Africa, 1998-2007. Malar J. 2008;7:162. 
39. Pagès F, Houze S, Kurtkowiak B, Balleydier E, Chieze F, Filleul L. Status of imported malaria on Réunion Island in 2016. Malar J. 2018;17:210.

40. Galappaththy GN, Fernando SD, Abeyasinghe RR. Imported malaria: a possible threat to the elimination of malaria from Sri Lanka? Tropic Med Int Health. 2013;18(6):761-8

41. Chen LH, Leder K, Barbre KA, Schlagenhauf P, Libman M, Keystone J, et al. Business travelassociated illness: a GeoSentinel analysis. J Travel Med. 2018; 25(1):1-10.

42. Coulibaly D, Travassos MA, Tolo Y, Laurens MB, Kone AK, Traore K, et al. Spatio-temporal dynamics of asymptomatic malaria: bridging the gap between annual malaria resurgences in a Sahelian environment. Am J Trop Med Hyg. 2017;97(6):1761-9.

43. Guillebaud J, Mahamadou A, Zamanka H, Katzelma M, Arzika I, Ibrahim ML, et al. Epidemiology of malaria in an area of seasonal transmission in Niger and implications for the design of a seasonal malaria chemoprevention strategy. Malaria J. 2013;12:379

44. Tejedor-Garavito N, Dlamini N, Pindolia D, Soble A, Ruktanonchai NW, Alegana V, et al. Travel patterns and demographic characteristics of malaria cases in Swaziland, 2010-2014. Malar J. 2017:16:359.

45. Arab A, Jackson MC, Kongoli C. Modelling the effects of weather and climate on malaria distributions in West Africa. Malaria J. 2014:13:126.

46. Wardrop NA, Barnett AG, Atkinson JA, Clements AC. Plasmodium vivax malaria incidence over time and its association with temperature and rainfall in four counties of Yunnan Province, China. Malar J. 2013;12:452.

47. Li SG, Yin SQ, Wang JZ, Li XS, Feng J. Shifting from control to elimination: analysis of malaria epidemiological characteristics in Tengchong County around China-Myanmar border, 2005-2014. Malar J. 2016;15:45.

48. Duan YZ, Li SG, Kang XH, Yin SQ, Sun XD. A point-like outbreak caused by secondary transmission from an imported malaria vivax case. Int J Med Parasit Dis. 2013;40:57-9.

49. Amoah B, Giorgi E, Heyes DJ, Burren SV, Diggle PJ. Geostatistical modelling of the association between malaria and child growth in Africa. Int I Health Geogr. 2018;17:7.

50. Mabaso ML, Vounatsou P, Midzi S, Da Silva J, Smith T. Spatio-temporal analysis of the role of climate in inter-annual variation of malaria incidence in Zimbabwe. Int J Health Geogr. 2006:5:20,

51. Mordecai EA, Paaijmans KP, Johnson LR, Balzer C, Ben-Horin T, Moor E, et al. Optimal temperature for malaria transmission is dramatically lower than previously predicted. Ecol Lett. 2013;16:22-30.

52. Kienberger S, Hagenlocher M. Spatial-explicit modeling of social vulnerability to malaria in East Africa. Int J Health Geogr. 2014;13:29.

53. Kazembe LN, Kleinschmidt I, Holtz TH, Sharp BL. Spatial analysis and mapping of malaria risk in Malawi using point-referenced prevalence of infection data. Int J Health Geogr. 2006;5:41.

54. Tonnang HE, Kangalawe RY, Yanda PZ. Review_-predicting and mapping malaria under climate change scenarios: the potential redistribution of malaria vectors in Africa. Malar J. 2010;9:1-10.

55. Tonnang HE, Tchouassi DP, Juarez HS, Igweta LK, Djouaka RF. Zoom in at African country level: potential climate induced changes in areas of suitability for survival of malaria vectors. Int J Health Geogr. 2014;13:12.

56. Githeko AK, Lindsay SW, Confalonieri UE, Patz JA. Climate change and vectorborne diseases: a regional analysis. Bull World Health Organ. 2000;78:1136-47.

57. Epstein PR. Climate change and human health. N Engl J Med. 2005;353:1433-6.

58. Haque U, Hashizume M, Glass GE, Dewan AM, Overgaard HJ, Yamamoto T. The Role of Climate Variability in the Spread of Malaria in Bangladeshi Highlands. PLoS ONE. 2010;5(12):e14341.

59. Hashizume M, Armstrong B, Hajat S, Wagatsuma Y, Faruque AS, Hayashi T, Sack DA. Association between climate variability and hospital visits for noncholera diarrhoea in Bangladesh: effects and vulnerable groups. Int J Epidemiol. 2007;36:1030-7.

60. Dewan A, Abdullah AY, Shogib MR, Karim R, Rahman MM. Exploring spatial and temporal patterns of visceral leishmaniasis in endemic areas of Bangladesh. Tropical Medicine and Health. 2017;45:29.

61. Bambrick H. Resource extractivism, health and climate change in small islands. International Journal of Climate Change Strategies and Management. 2018;10(2):272-88.

62. Elci MA, Sealy H. Pinkerton, Rom WN, editors. Global climate change and public health. Chapter 16; respiratory medicine 7, vol. 2014. New York: Springer Science+Business Media. p. 279-92.

63. UNFCCC. Climate change, small island developing states. Bonn: Issued by the Climate change secretariat (UNFCCC); 2005. p. 1-32.

Ready to submit your research? Choose BMC and benefit from:

- fast, convenient online submission

- thorough peer review by experienced researchers in your field

- rapid publication on acceptance

- support for research data, including large and complex data types

- gold Open Access which fosters wider collaboration and increased citations

- maximum visibility for your research: over $100 \mathrm{M}$ website views per year

At BMC, research is always in progress.

Learn more biomedcentral.com/submissions 